\title{
VON MEGALITHISCHEN KOPFJÄGERN, MITTELALTERLICHEN KRIEGERN, CHARLTON HESTON UND DER FILMANALYSE: EINFLÜSSE EINER PRÄHISTORISCHEN MUSIK-ETHNOLOGIE IM SCHAFFEN JUAN-EDUARDO CIRLOTS
}

\author{
Bernhard BLEIBINGER
}

\begin{abstract}
Pivotal creations within the works of the Spanish poet and art critic Juan-Eduardo Cirlot, as, for example, La Dama de Vallcarca and Bronwyn attest to tendencies of a new mythicization of the commonplace by means of reinterpreting a Barcelona neighbourhood as a megalithic landscape and figures from Hollywood films as elements of cosmic myths. As this article will demonstrate, the foundations and the origins are based on, among other things, models and conclusions of studies in the first half of the 20th Century, in the fields of Ethnology and Prehistory. As Cirlot's drafts have shown, those models and conclusions were imported through comparative musicology.
\end{abstract}

\section{Zusammenfassung}

Zentrale Schöpfungen im Euvre des spanischen Kunstkritikers und Poeten Juan-Eduardo Cirlot, wie z.B. La Dama de Vallcarca und Bronwyn, zeugen von Tendenzen einer Remythisierung des Alltäglichen, indem ein Stadtteil Barcelonas in eine megalithische Landschaft und Figuren aus Hollywoodfilmen in Elemente kosmischer Mythen umgedeutet werden. Ausgangspunkt und Grundlage bilden - wie im vorliegenden Beitrag gezeigt wird - u.a. Modelle und Erkenntnisse aus der kulturhistorischen Ethnologie und der Frühgeschichte der ersten Hälfte des 20. Jahrhunderts. Wie Skizzen Cirlots belegen, wurden diese über die vergleichende Musikwissenschaft in sein Werk importiert.

„Bronwyn, mi corazón, si nunca has existido eres posible porque la realidad es muerte viva. Bronwyn, mi corazón, tócame con tu nada y con tu nunca.“
„Bronwyn, mein Herz, wenn du niemals existiert hast, so bist du doch möglich da die Realität lebendiger Tod ist.

Bronwyn, mein Herz, berühre mich mit deinem Nichts und mit deinem Niemals"1

Der Kreis ist erlesen an jenem vierten Mai 2005, 22 Uhr, in der Kapelle des alten Hospital de la Santa Creu - die Professorinnen für Literatur und Architektur, Victoria und Lourdes Cirlot, und der

1. Juan Eduardo Cirlot: Bronwyn (1967), aus: ders. Bronwyn, Madrid: Siruela 2001, S. 81. Obige und alle folgenden Übersetzungen vom Autor des vorliegenden Beitrags. 
Maler Beneyto, um nur drei Personen aus der illustren Gesellschaft zu nennen, die im Begriff steht, ein zeitloses Ritual zu vollziehen: Das elitäre Credo an ein gemeinsames Identifikations- und (Szene-) Kultursymbol. Ein profanes Gemisch aus den verschiedenen Sprachen Spaniens, aus Englisch und Arabisch lässt vor den Türen den vom Geruch von Schweiß, Hundekot und Zweitaktmotoren erfüllten stickigen und schon sommerlichen Abenddunst in der Carrer de L'Hospital hektisch pulsieren, während in der Kapelle allmählich parfümierte, erwartungsvolle, ja sakralisierte Ruhe einkehrt. Eine Leinwand ziert die Apsis, gleich einem Altar. Davor haben sich drei Literaten, ihrer Rolle gemäß, erhaben und gespielt leger in Sesseln postiert. Nach der Begrüssung durch Victoria Cirlot folgen einführende Worte durch einen der Literaten - entgegen der hiesigen Gepflogenheit nicht auf Katalanisch. Antoní Gaudí starb hier, erfahren wir, und das Gebäude soll einen engen Bezug zu jener Person haben, deren Schaffen nun gewürdigt werden soll: Juan-Eduardo Cirlot, ein katalanischer Poet und Kunstkritiker, der nur auf Castellano veröffentlichte, der gleichsam gemieden wie verehrt wird. Dann beginnt die Vorführung. Zu einem Gedicht über Susan Lenox laufen im Hintergrund Ausschnitte aus Filmen mit Clark Gable und Greta Garbo. Wir lauschen den rhythmisch monotonen Worten eines desillusionierten, Wein trinkenden Verbalathleten in der Bar, bevor uns Variationen auf Bronwyn und Bronwyn en Barcelona in ein mittelalterliches Ambiente hinüberführen, in dem Raum und Zeit in mythischen Variationen des 20. Jahrhunderts ineinander verfließen, in dem Charlton Heston und Rosemary Forsyth die Hauptrolle spielen. Cirlot wird an jenem Abend so präsentiert wie er sich selber gerne darzustellen pflegte: als Zwischenweltswandler und kryptisch wie ein Symbol, dem Verbindungsglied im intermediären Reich zwischen der Welt der Ideen und der materiellen Welt.

Doch man würde ihm nur einseitig gerecht, betrachtete man ihn schlicht unter dem Aspekt seines Euvres als fertiges Endprodukt und der damit zusammenhängenden Selbstdarstellung.

„Er [Cirlot] war kein Genius im Sinne eines Rimbaud, aber er hatte viel Talent. Als Kunstkritiker war er sehr bekannt. In Spanien gilt er als der beste Kritiker seiner Zeit, [...]. Um sein Werk gut zu verstehen ist es notwendig zwei fundamentale Bücher von Marius Schneider zu kennen, die kaum jemand gelesen hat, 'El origen musical de los animales-símbolos' und 'La danza de espadas y la tarantela'،"2

Wie obigem Zitat von Pere Gimferrer zu entnehmen ist, existieren Vorbedingungen zu einem profunderen Werkverständnis, nämlich die Lektüre von El origen musical de los animales-símbolos ${ }^{3}$ und La danza de espadas y la tarantela ${ }^{4}$ von Marius Schneider, einem aus dem Elsass stammenden Musikethnologen.

2. „No era un genio en el sentido en que lo fuera Rimbaud, pero tenía mucho talento. Como crítico de arte era muy reconocido. En España es el mejor crítico de su época, [...]. Para comprender bien su obra es necesario conocer los dos libros fundamentales de Marius Schneider, que apenas nadie ha leído, 'El origen musical de los animales-símbolos' y 'La danza de las espadas y la tarantela'." Pere Gimferrer über Cirlot, in: Arte, 4, No. 19, (Enero-Febrero 1997), S. 49.

3. Marius Schneider: El origen musical de los animales-símbolos en la mitología y la escultura antiguas. Ensayo históricoetnográfico sobre la subestructura totemística y megalítica de las altas culturas y su supervivencia en el folklore español, Monografías I, Barcelona 1946. Im folgenden Beitrag stütze ich mich auf den von Victoria Cirlot herausgegebenen und im Verlag Siruela Madrid erschienenen Nachdruck von 1998.

4. Marius Schneider: La danza de espadas y la tarantela. Ensayo musicológico, etnográfico y arqueológico sobre los ritos medicinales, Monografías III, Barcelona 1948. 
Im folgenden Beitrag werde ich versuchen, der Rolle Schneiders im Werk Cirlots nachzuspüren, indem ich einige Aspekte ihrer Biografien, Ideengebäude und ihres Schaffens beleuchte. Den Anlass dazu bietet die Tatsache, dass im musikwissenschaftlich-musikethnologischen Bereich bisher kaum Publikationen dazu vorliegen. ${ }^{5}$ Eine Gesamtwerkbetrachtung schließt sich aufgrund des gegebenen Rahmens aus.

\section{Cirlot und Schneider}

Juan-Eduardo Cirlot wurde am 9. April 1916 geboren und entstammte einer Familie, die väterlicherseits auf eine lange militärische Tradition zurückblicken konnte. Sowohl sein Vater, Juan Cirlot Nieto, als auch sein Großvater, Juan Cirlot Butler, standen im Dienste Spaniens. Letztgenannter, der Sohn des Brigadiers Juan Cirlot y Espí und der aus Irland stammenden Tochter des Vizeadmirals Butler, bekleidete auf den Philipinen zeitweise das Amt des Gouverneurs. Von nicht minder angesehener Abstammung war die Mutter, María Laporta Blanco, deren Vater, Francisco Laporta, mit König Alfonso XIII. sogar in freundschaftlichem Verhältnis gestanden haben soll. $^{6}$

Die Schuljahre verbrachte Juan-Eduardo Cirlot im Jesuitenkolleg in der Calle Caspe, und es ist davon auszugehen, dass aus dieser Zeit seine besondere Faszination für die römische Antike, für Zeremonien und Rituale rührt. Als geradezu von zentraler Bedeutung sollten sich die sommerlichen Aufenthalte der Familie in der Villa Branca in Sant Cugat erweisen. Wie späteren Aufzeichnungen Juan-Eduardo Cirlots zu entnehmen ist, nahm er Sant Cugat als Beginn einer Pilgerfahrt und als Ort der Rückkehr wahr. Von Sant Cugat handelte auch das Buch jenes Autors, der ihn in die Symbologie initiierte, Marius Schneider, doch davon wird weiter unten noch berichtet. ${ }^{7}$

Im Alter von 13 Jahren ereignete sich für Juan-Eduardo Cirlot eine dramatische Wende als er aus dem Kollegium genommen wurde. Mangelndes Interesse an kulturellen Dingen seitens seiner Eltern dürfte neben dem Finanziellen ein Hauptbeweggrund zu diesem Schritt gewesen sein. Während der anschließenden Lehrzeit in einer Bank empfand sich Juan-Eduardo als „Maschine“, als ,lebender Toter" in einem Büro. Seinen Studien konnte er nur noch autodidaktisch nachgehen, akademische Titel blieben ihm verwehrt. Lediglich die Piano- und Kompositionskurse an der Academía von Fernando Ardévol und das private Studium der ernsten Musik bei seiner Tante Emilia, einer Pianistin, eröffneten ihm einen Lichtblick. Doch auch diese Phase der musikalischen Geistesweitung endete abrupt und tragisch, als Juan-Eduardo Cirlot 1950 in einem Anfall von Frustration und im Beisein von Modest Cuixart mit den Worten „Das ist Schönberg!“ seine Partituren zerstörte. Spanien wäre schwierig für jede Art intellektueller Betätigung und ein unmöglicher Ort für die Musik,

5. Cirlot wurde vor allem in der spanischen Literaturwissenschaft und Symbolforschung rezipiert, insbesondere durch Jaime D. Parra und Victoria Cirlot. Ich möchte an dieser Stelle Frau Montserrat Prat und meinen Kollegen vom BRI (Barcelona Recerca de l'Imaginari) für ihre Anregungen danken.

6. Lourdes y Victoria Cirlot: Juan-Eduardo Cirlot: Un boceto biográfico, in: Barcarola, No. 53, (Junio 1997), S. 53-54.

7. Lourdes y Victoria Cirlot: Juan-Eduardo Cirlot: Un boceto biográfico, S. 54-55. 
argumentierte er. Des weiteren hätte auch die Unterbrechung seiner musikalischen Studien durch den Bürgerkrieg die Fortführung seiner Arbeit in diese Richtung behindert. ${ }^{8}$

In der Tat wurde seine musikalische Schaffensperiode durch den Militärdienst im republikanischen Heer und in der Armee Francos für sieben Jahre unterbrochen, doch gelangte er während jener Zeit durch eine Gruppe von Intellektuellen in Zaragoza, und insbesondere durch Alfonso Buñel, in Kontakt mit dem Surrealismus. Obgleich sich Cirlot nie absolut mit dieser Richtung identifizierte, verteidigte er sie ebenso wie er sich für andere Äußerungsformen der „Avantgarde“ einsetzte. Der Surrealismus half mit, seine Leidenschaft für das Phantastische zu stillen, und erschien ihm als ein Werkzeug zur Traumdeutung. Cirlot notierte seine Träume und unternahm Versuche ihrer Interpretation. Der Surrealismus eröffnete ihm hier neue Wege, da er die im Schlaf erscheinenden Bilder entscheidender und von größerer Wichtigkeit erachtete als jene der Tagwelt. Konkrete Antworten offerierte er jedoch kaum. Es sollte daher nicht der Surrealismus sein, der Cirlots bekannteste Werke beeinflusste. ${ }^{9}$

Nach seiner Rückkehr nach Barcelona im Jahr 1943 und der Wiederaufnahme seiner Arbeit in der Banco Hispanoamérica, traf sich Cirlot im Café Suizo regelmäßig mit Intellektuellen, verfaßte erste poetische Schöpfungen wie Canto de la vida muerta und begann sich als Kunstkritiker zu betätigen. 1947 wechselte er von der Bank in den Verlag „Argos“ in der Nähe der Galerías Layetanas, und von 1951 bis zu seinem Tod war er für den Verlag „Gustavo Gili“ tätig, mit dem er seit seiner Arbeit über Strawinsky, einem seiner Lieblingskomponisten, in Verbindung stand. Gerade die oberflächlich vielleicht unscheinbar anmutenden Jahre zwischen 1947 und 1951 sollten für Cirlots späteres Schaffen eine zentrale Bedeutung erlangen, nämlich durch Kontakte zu Künstlergruppen und Wissenschaftlern wie „Dau al Set“ und Marius Schneider. ${ }^{10}$

„Dau al Set“ wurde im September 1948 durch die Maler Joan Josep Tharrats, Antoni Tàpies, Modest Cuixart und Joan Ponç, den Schriftsteller Joan Brossa und den Kunstkritiker Arnau Puig gegründet und verfügte von Beginn an über ein eigenes Informationsorgan, der Revista Dau al Set, in der Erscheinungen wie der Dadaismus, der Surrealismus oder die Musik Arnold Schönbergs besprochen wurden. Cirlot trat der Gruppe im Jahr 1949 bei und betätigte sich als Verfasser von Artikeln, Kritiken und Essays. Der ersten Phase einer weitgehend öffentlich akzeptierten Propaganda, folgte von 1953 bis 1966 eine Zeit der Verteidigung neuer Strömungen, wie etwa des Informalismo, in der sich Cirlot gezwungen sah, die Neuorientierung seiner Kollegen zu rechtfertigen. Er selbst

8. Lourdes y Victoria Cirlot: Juan-Eduardo Cirlot: Un boceto biográfico, S. 56; Instituto Valenciano de Arte Moderno (Hrsg.): Mundo de Juan Eduardo Cirlot, Ausstellungskatalog, IVAM Centre Julio González 19 septiembre al 17 noviembre 1996 , Valencia 1996, S. 233-234, 343; vgl. Jaime D. Parra: La música como base estructuradora de la obra de Juan-Eduardo Cirlot, in: Aedom, Año 5, No. 1, (Enero-Junio 1998), S. 7-73). Jaime Parra führt das Musikalische im Schaffen Cirlots nicht nur auf Schönberg und Skrijabin, sondern auch auf Schneider zurück. Schönbergs Einfluß spiegelt sich u.a. - dies sei hier nur angemerkt - in Gedichten aus den Bronwyn-Zyklen wider, die als „Permutaciones“ betitelt sind. Cirlots „Permutaciones“ sind so aufgebaut, dass Wörter, Phrasen und teils ganze Sätze untereinander austauschbar sind und dadurch der Inhalt des Gedichts neue Wendungen nimmt. Permutationen im Sinne von Neuordnungen des Wesentlichen führen so zu neuer Sinnstiftung. Als musikalischen Verweis auf Schönberg möchte ich eine der wenigen erhaltenen Kompositionen Cirlots, die Suite Atonal (Sätze: I. Preludio, II Himno, III Interludio, IV Coral, V Fuga) für Piano von 1947, anführen. Sie ist wiedergegeben in genanntem Band der Reihe Barcarola auf den Seiten 102-104.

9. Lourdes y Victoria Cirlot: Juan-Eduardo Cirlo: Un boceto biográfico, S. 58.

10. Gemma Mañá Delgado: <Los Cantos de la vida muerta > Y El lenguaje poético de Juan-Eduardo Cirlot, in: Barcarola, No. 53, (Junio 1997), S. 123-136; Lourdes y Victoria Cirlot: Juan-Eduardo Cirlot: Un boceto biográfico, S. 58-59. 
distanzierte sich ebenfalls vom Surrealismus und behandelte ihn aus der Perspektive des Historikers und Essayisten. ${ }^{11}$ Jedoch blieb seine Liebe für das Phantastische und für Symbole erhalten, in anderen Worten: Er verlor nie seinen Blick für besondere Momente (in) der Alltagskultur.

Die Verbindung zu Marius Schneider bahnte sich über dessen Monographien und Artikel El origen musical de los animales-simbolos (1946) und La danza de espadas y la tarantela (1947/1948) an, wie Cirlots Beitrag Musicalismo mágico in seinem Diccionario de los Ismos von $1949 \mathrm{zu}$ entnehmen ist. ${ }^{12}$ Die zwei Beiträge Hacia una ciencia de los símbolos und El ojo en la mitología aus den Jahren 1952 und 1954 sind bereits auf persönliche Kontakte zurückzuführen. ${ }^{13}$

Marius Schneider war zu Beginn des Jahres 1944 auf Einladung des Leiters der Musikabteilung der Biblioteca de Catalunya und des Instituto Español de Musicología (I.E.M.) am Consejo Superior de Investigaciones Científicas, Mons Higini Anglès i Pamies, nach Barcelona gekommen. Den erhaltenen Dokumenten zufolge hatten ihn persönliche und wissenschaftliche Differenzen mit Herbert Gerigk (Sonderstab Musik) zu diesem „Wohnortwechsel“ veranlasst. Schneider hatte zuvor, 1943, versucht, seine Ernennung zum Kustos am Staatlichen Institut für Deutsche Musikforschung zu erwirken, doch scheiterte dieses Vorhaben, ähnlich wie schon seine angestrebte Habilitation (19341937), aufgrund politischer Beurteilungen, in denen er als weltfremder, katholischer Intellektueller ohne völkischen Standpunkt beschrieben wurde. Informationen Guillaume de Vans, wonach Schneider ihm gegenüber ,,in aller Form seine antinationalsozialistische Grundhaltung zum Ausdruck ${ }^{\text {“14 }}$ gebracht hätte, gaben Gerigk Anfang 1944 eine neue Handhabe, und es ist davon auszugehen, dass Schneider dies ahnte. Noch von Paris aus bat er Anglès um eine offizielle Einladung zur Arbeit am I.E.M., und nur wenige Monate später trat er seinen Dienst als Leiter der dortigen „sección folklore“ an. Sein Aufgabengebiet umfasste die musikethnologische Ausbildung seiner Mitarbeiter, die Organisation von Sammelaktivitäten für den „Cancionero Musical“ und die Herausgabe desselben. Darüber hinaus war er verpflichtet, Beiträge für das Institutsorgan, Anuario Musical, zu verfassen. ${ }^{15}$ Seine Tätigkeit fällt aus heutiger Sicht vorwiegend in den Bereich der musikalischen Volkskunde und könnte als hispanozentrisch gewichtet beschrieben werden. Es ist sehr wahrscheinlich, dass Schneider, der seine musikethnologische Ausbildung bei Curt Sachs und Erich Moritz von Hornbostel genossen, von 1934 bis offiziellerweise 1945 das Berliner Phonogramm-Archiv geleitet und Klangdokumente aus aller Welt verwaltet hatte, darin eine Einschränkung sah. Jedoch wusste er Auswege in Form von Beiträgen, die zwar dem Titel nach auf spanisches Kulturgut Bezug nahmen, sich aber inhaltlich mit ethnologischen wie musikethnologischen Erscheinungen und Diskussionen außerhalb Spaniens

\footnotetext{
11. Lourdes y Victoria Cirlot: Juan-Eduardo Cirlot: Un boceto biográfico, S. 59-62.

12. Juan-Eduardo Cirlot: Diccionario de los Ismos, Barcelona 1949, S. 238.

13. Von den Beiträgen berichtet Victoria Cirlot in: Notas sobre M.Schneider Y J.E.Cirlot, in: Rosa Cúbica, No. 10, (Primavera 1993), S. 94.

14. Herbert Gerigk, Hauptamt Wissenschaft/Amt Wissenschaftsbeobachtung und -wertung an die Partei-Kanzlei, 16.3.1944, Institut für Zeitgeschichte München, MA-116/15 (Microfilm). Weiter heißt es, Schneider habe ,eine Einstellung in der Judenfrage an den Tag gelegt, die der nationalsozialistischen völlig entgegensteht“. Damit wurde nur wiederholt, was Gerigk am 4.1.1944 an das Hauptamt Wissenschaft geschrieben hatte.

15. Zu Schneiders vereitelter Habilitation und Ernennung zum Kustos sowie zu seiner Tätigkeit in Barcelona siehe: Bernhard Bleibinger: Marius Schneider und der Simbolismo. Ensayo musicológico y etnológico sobre un buscador de símbolos, Alteritas, Münchner ethnologische Impressionen Vol. 2, München-Pondicherry 2005, S. 30-34 und 67-83.
} 
auseinander setzten. Als besonderes Beispiel muss hier El origen musical de los animales-símbolos en la mitología y la escultura antiguas. Ensayo histórico-etnográfico sobre la subestructura totemística y megalítica de las altas culturas y su supervivencia en el folklore español ${ }^{16}$ erwähnt werden. Wie bereits dem Titel zu entnehmen ist, widmet sich Schneider darin totemistischen und megalithischen Substrukturen in den Hochkulturen und deren Überleben in der spanischen Folklore. Seine Materialsammlung stammte jedoch aus aller Welt.

Es dürften zunächst vor allem Möglichkeiten zur Traumdeutung gewesen sein, die Cirlot an Schneider interessierten, zumal El origen Theorien zur menschlichen Wahrnehmung, zum primitiven Denken sowie zur Wirkung und Verbreitung von Symbolen behandelt. Darüber hinaus sah er darin neue Wege zur Betrachtung moderner Kunst, und er selbst ließ die Symbologie seines neuen Meisters schließlich in sein eigenes Schaffen einfliessen. La Dama de Vallcarca, eine virtuelle Reise durch Vallcarca, einen Stadtteil Barcelonas, basiert auf Schneiders mystischer Landschaft, einem in $E l$ origen (re-)konstruierten megalithischen Weltbild, und das 1958 erstmals erschienene Diccionario de Símbolos ist Schneider gewidmet und beginnt mit ausführlichen Erläuterungen zu dessen symbologischen Theorien. In den 1960er Jahren ist Schneiders Einfluss in Cirlots Analyse von Franklin Schaffners Film „El Señor de la Guerra“ (englischer Titel: The War Lord) und den darauf folgenden Zyklen über Bronwyn festzustellen. Nach der Auffassung Cirlots basierte der Film auf mythischen Symbolen und Strukturen, wie er sie aus Schneiders Weltbild, dem „paisaje schneideriano“, kannte. Bis zu Beginn der 1970er Jahre äußerte er sich in La Vanguardia über die Bedeutung Schneiders in der Symbolforschung. ${ }^{17}$

Das Verhältnis zwischen Cirlot und Schneider mag aus heutiger Sicht indessen etwas sonderbar anmuten, denn es kam nie zu gegenseitigen Freundschaftsbesuchen. ${ }^{18}$ Man traf sich - wie Peripatetiker - zu abendlichen Spaziergängen, auf denen Schneider sein Wissen über Symbole ausbreitete. ${ }^{19} 1958$ brach der Kontakt zwischen den beiden für einige Jahre ab. Cirlot hatte Schneider zuvor ein Exemplar des ihm gewidmeten Diccionario de Símbolos zukommen lassen, für das ihm der Musikethnologe mit dem Hinweis dankte, dass dieses Geschenk der Hochachtung und Freundschaft, ihm nach der „miserablen“ Verabschiedung aus dem „Instituto de Musicología“ die gute Erinnerung an Spanien bewahrt hätte. ${ }^{20}$

16. Marius Schneider: El origen musical de los animales-símbolos en la mitología y la escultura antiguas. Ensayo histórico-etnográfico sobre la subestructura totemística y megalítica de las altas culturas y su supervivencia en el folklore español, Monografías I, Barcelona 1946. Teile daraus wurden 1955 (Bärenreiter Kassel) und 1978 (Heimeran München) unter dem Titel Singende Steine in deutscher Sprache veröffentlicht. Im vorliegenden Beitrag stütze ich mich bei der Darstellung von Schneiders Theorien vor allem auf El origen.

17. Beispielsweise in: ¿Qué es la Simbología?, La Vanguardia, 23.11.1968; La Simbología de Marius Schneider: Homenaje a un gran maestro, La Vanguardia, 14.3.1969; Simbolismo fonetico. Sobre el lenguaje (I-III), La Vanguardia, 14.2, 17.2 und 18.3.1970; Temas de hoy. Actualidad de la Simbología, La Vanguardia, 30.12.1970.

18. Für diese Information möchte ich an dieser Stelle Victoria Cirlot danken.

19. Juan-Eduardo Cirlot: Homenaje A Un Gran Maestro: La Simbología De Marius Schneider, in: La Vanguardia, 14. März 1969, S. 11.

20. Victoria Cirlot: Notas sobre M. Schneider y J. E. Cirlot, in: Rosa Cúbica, No. 10, (Primavera 1993), S. 99. Wörtlich heißt es im darin zitierten Schreiben Schneiders: ,[...] me siento indigno de verme señalado tan amistosamente en su dedicatoria, pero es una gran satisfacción después que el Instituto de Musicología, al cual di tanto trabajo mío, me despidió de una manera tan miserable. Usted salva el recuerdo que me queda de España. Y por lo tanto le agradezco aun más.

Un saludo afectuoso siempre su amigo

Marius Schneider“ 
Schneider war Cirlot mehr als nur ein Gelehrter, dessen Ideen er rezipierte. Er war ihm ein polysignifikantes Symbol.

„Alto, delgado, tenía el don de no ser ni un artista, ni un erudito, sino algo que no sabría definir. Un sabio y a la vez un artesano o un guerrero. [...] No es un Eliade.“21

Das von Cirlot verwendete Vokabular eröffnet hier wie ein Symbol Betrachtungs- und Beziehungsmöglichkeiten, indem Schneider nicht als Wissenschaftler, der ihn in eine Symbolkunde initiierte hatte, sondern gleichermaßen als Weiser (sabio), Handwerker (artesano) und Krieger (guerrero) beschrieben wird. Die Begrifflichkeiten verweisen auf Schneiders Landschaft und Cirlots Bronwyn, und es ist davon auszugehen, dass die Wertschätzung für Schneider, die Faszination für dessen Lebensweg, aber auch die Sicht der Dinge aus der Warte des Poeten dafür ausschlaggebend waren. Cirlot glaubte an die Wiedergeburt und wähnte sich in gewisser Weise selbst als ,guerrero medieval“", als mittelalterlichen Krieger, als Chrysagon, den Herrn des Krieges in Franklin Schaffners „El Señor de la Guerra“. ${ }^{22}$ Schneider hatte ihn das zur Analyse jenes Films notwendige Werkzeug in die Hand gegeben, und Cirlot betrachtete ihn nun durch dieses Raster. Es ist anzunehmen, dass er darüber hinaus eine Schicksalsverbindung mit seinem Lehrer fühlte, den bis heute der Nimbus des „guerrero“, des „militar“ und Doppeldissidenten umgibt, wie folgender Äußerung Pere Gimferrers zu entnehmen ist.

„Schneider war Angehöriger von Rommels Afrikatruppe, der als politischer Flüchtling nach Barcelona kam (in gewissem Sinne ein Doppeldissident, zumal schon Rommel bei einer Verschwörung gegen Hitler starb).“23

Nach 1969 brach die Verbindung zu Schneider ein weiteres Mal ab. Zwar versuchte Cirlot im Oktober 1972 über Julius Schwabe noch einmal dessen Adresse herauszufinden, doch kam es zu keiner Kontaktaufnahme mehr. Acht Monate später erlag Juan-Eduardo Cirlot einem Krebsleiden. ${ }^{24}$

\section{Das Weltbild - el paisaje schneideriano}

Wie bereits erwähnt, sollte insbesondere Schneiders Monografie El origen musical de los animales-símbolos eine zentrale Bedeutung im Euvre Juan-Eduardo Cirlots erlangen. Der Grund

21. Juan-Eduardo Cirlot über Schneider, in: Victoria Cirlot, Notas Sobre M. Schneider Y J.E. Cirlot, in: Rosa Cúbica, No. 10, (Primavera 1993), S. 97. Von einer Übersetzung des obigen Zitates wurde abgesehen, da sie den semantischen Gehalt zerstören würde.

22. Jaime D. Parra: El poeta y sus símbolos. Variaciones sobre Juan Eduardo Cirlot, Barcelona 2001, S. 81-82; Pere Gimferrer: Proyecto y Realización: El Universo de Juan-Eduardo Cirlot, in: Barcarola, No. 53, (Junio 1997), S. 157.

23. „Schneider era un militar de la legión de Rommel, de África, que vino como refugiado político a Barcelona (en cierto sentido un doble disidente, si ya Rommel acabó conspirando contra Hitler)." Pere Gimferrer: Proyecto y Realización: El Universo de Juan-Eduardo Cirlot, in: Barcarola, No. 53, (Junio 1997), S. 158.

24. Victoria Cirlot: Notas Sobre M. Schneider Y J.E. Cirlot, in: Rosa Cúbica, No. 10, (Primavera 1993), S. 98. 
dafür ist in der unkonventionell anmutenden Herangehensweise an Fragen zu musikalischen Symbolen, deren Bedeutung, Verbreitung und Ursprung $\mathrm{zu}$ suchen. Schneider arbeitete interdisziplinär. Die inhaltliche Gewichtung in $\mathrm{El}$ origen verweist beispielsweise auf eine kulturhistorische und diffusionistische Sichtweise aus dem Bereich der Ethnologie und der Frühgeschichte. Den Ausgangspunk bilden Überlegungen psychologischen Charakters zum menschlichen Denken, das sich, nach Schneiders Auffassung, dadurch vom tierischen absetzt, dass es auf der Fähigkeit zur Analogiebildung und der rhythmischen Identifikation beruht; Analogien entstehen u.a. durch einen Beziehungsstiftenden Faktor, den er ,ritmo común“, gemeinsamen Rhythmus, nennt. ${ }^{25}$ Nach Schneider erlebte der Mensch seine Umwelt in Form von lebenden Rhythmen und - ähnlich wie in Max Wertheimers Gestaltpsychologie - als rhythmische Gestalten bzw. Ganzheiten. Als polyrhythmisches Wesen sei er darüber hinaus in der Lage gewesen, spezifische Rhythmen zu imitieren. Diese Gabe nutzte er in prätotemistischen und totemistischen Kulturen, um seine Jagdbeute zu „dominieren“, und er integrierte sie in Kulte, indem er Tierstimmen nachahmte und in seinem eigenen Ordnungssystem unterbrachte; etwa wenn Tierstimmen ihren Qualitäten nach Zeiten zugeordnet wurden. ${ }^{26}$ Die ursprünglich realistische Imitation wurde in ,höheren Kulturen“ schließlich kultiviert und wandelte sich in eine ästhetische, musikalische Imitation. Aus Tier-RufSymbolen entstanden Klangsymbole, sonidos-símbolos.

„Es scheint, dass sich, auf eine generelle Weise, die realistische Imitation Stück für Stück in eine mehr oder weniger ästhetische und gestützt durch die Erschaffung von Musikinstrumenten, von denen jedes eine bestimmte mystische Rolle einnahm, eigenständige musikalische Imitation wandelte. In landwirtschaftlichen Kulturen werden natürliche Rhythmen geebnet und reguliert. Willkürliche Formen werden in kultivierte Formen verwandelt in dem Maße wie der menschliche Geist sie dem Gesetz der Symmetrie und der Proportion aussetzt. Durch ihre melodischen Bögen, ihre Texte und eingefügten Rufe repräsentieren diese kultiviertesten Formen weiterhin Tänze der Tiere, aber durch die Aufgabe der realistischen Imitation wurde der mystische Wert dieser Tänze gemindert. Die grítos-símbolos ${ }^{27}$ mussten sich in sonidos-símbolos ${ }^{28}$ verwandeln, die durch eine relative Distanz, jedoch nicht durch eine absolute Tonhöhe, zusammenhingen. “'29

25. Stark vereinfacht ausgedrückt: Der Mensch versuchte das Unbeschreibbare durch das Beschreibbare und Bekannte zu erklären und in seiner Ideenwelt fassbar zu machen. Die Assoziationsstiftung geschieht durch ein gemeinsames Element, den Faktor S, der in Schneiders Terminologie auch als rhythmisches Prinzip, als „ritmo común“, beschrieben wird. Unabhängig davon, doch ähnlich, äußert sich später Gilbert Durand. Er spricht von einer dritten Qualität B. Hierzu: Marius Schneider: El origen, S. 17-49; Bernhard Bleibinger: Marius Schneider und der Simbolismo, S. 183-195; vgl. Gilbert Durand: Lo imaginario, Colección Textos del Bronce, Barcelona 2000, S. 103-104.

26. Bernhard Bleibinger: Marius Schneider und der Simbolismo, S. 183-201.

27. Gemeint sind Lautsymbole, die mit der Tierstimmenimitation in Verbindung stehen.

28. Gemeint sind hier klingende Symbole, die bereits mit Tönen im musikalischen Sinne verglichen werden können.

29. „De una manera general, parece que la imitación realista se transformó poco a poco en una imitación propiamente musical más o menos estética y apoyada por la creación de instrumentos musicales, cada uno de los cuales desempeña un papel místico determinado. En las culturas agrícolas los ritmos naturales se allanaron y se regularizaron. Las formas arbitrarias se transformaron en formas cultas, a medida que el espíritu humano las sometió a la ley de la simetría y de la proporción. Por sus curvas melódicas, su letra y los gritos intercalados estas formas más cultas siguieron representando bailes de animales, pero el abandono de la imitación realista disminuía el valor místico de estos bailes. Los gritos-símbolos debieron de transformarse en sonidos-símbolos relacionados por una distancia relativa, mas no por una altura absoluta." Marius Schneider: El origen, S. 377. 
In der Folge kultischer Rationalisierungsprozesse entstanden daraus wiederum Korrespondenzsysteme bzw. -tabellen, in denen Töne u.a. mit Planeten, verschiedensten Lebewesen, Mineralien, Musikinstrumenten und der Himmelshierarchie in Verbindung gesetzt werden konnten. $\mathrm{Da}$ die herangezogenen Korrespondenzsysteme aus Indien, China und dem Abendland Übereinstimmungen aufwiesen, ging Schneider von einem gemeinsamen mythologischen Ursprung und einer Trägerkultur aus. Beides versuchte er in El origen zu lokalisieren, indem er die ihm bekannten Korrespondenzen vereinte, mit Elementen aus verschiedensten Mythen sowie mit den dazu gehörenden Weltbildern in Verbindung brachte und daraus das vermeintliche, auf dem Quintenzirkel basierende, Urweltbild jener Urkultur rekonstruierte.

„Es wurde wiederholt auf Gebirge und Tal, auf Flüsse, Seen und Wege, auf Tore und Treppen hingewiesen. Dies macht uns geneigt zu glauben, dass der Quintenzirkel nicht nur eine Ideologie widerspiegelt, sondern auch die Landschaft, die der Mensch während seines Lebens und seines Todes durchquert, indem er der selben Richtung wie der Mond folgt, dessen vier Phasen den Verlauf des menschlichen Lebens repräsentieren. Diese Landschaft könnte der Schlüssel für die zahlreichen fundamentalen Konkordanzen zwischen den verschiedensten Mythologien sein. Indem wir diese mystische Landschaft und einen weiter entwickelten Kanon der Formen als Basis nehmen, können wir uns einem detaillierteren Studium der inneren Struktur dieser Mythologie widmen. Fürs erste werden wir in lámina XIV diese Landschaft einzig anhand der Daten, die die vorherigen Kapitel lieferten und durch Elemente, die die Studie über das Ewe beitrug [...], dessen Vokalismus Relikte einer alten mystischen und geheimen Sprache erkennen zu lassen scheint, skizzieren. ${ }^{\text {“30 }}$

Die Möglichkeit zur Tonzuordnung war über erhaltene Korrespondenzsysteme gegeben, von denen Schneider einige jedoch modifizierte. ${ }^{31}$ Über sie leitete er beispielsweise einen in Quinten angelegten solaren Tierkreis ab, ${ }^{32}$ der im Weltbild ein primäres strukturierendes Prinzip bildete. Hinter dem in Quintenzirkel angelegten Weltbild stand - nach Schneider - vermutlich eine Geheimlehre. ${ }^{33}$ Man sollte m.E. dabei aber nicht Schneiders Idee der Evolution von Tonarten durch Quintenschichtung, wie sie etwa schon in seiner Geschichte der Mehrstimmigkeit durchschimmert, außer Acht lassen, ${ }^{34}$ d.h. es ist nicht auszuschließen, dass ein Vor-Urteil ${ }^{35}$ existierte, das notwendigerweise zur quintisch-zyklischen Anlage rekonstruierter Weltbilder führte.

30. „Repetidas veces se han mencionado montaña y valle, ríos, lagos y caminos, puertas y escaleras. Esto nos inclina a creer que el círculo de quintas no sólo representa una ideología, sino también el paisaje que el hombre atraviesa durante su vida y su muerte, siguiendo la misma dirección que la Luna, cuyas cuatro fases representan la evolución de la vida humana. Este paisaje podría dar la clave para las numerosas concordancias fundamentales entre las mitologías más diferentes. Tomando como base este paisaje místico y un canon de formas más desarrollado nos proponemos dedicar un estudio más detallado a la estructura interna de esta mitología. Por lo pronto esbozaremos en la lámina XIV este paisaje únicamente con los datos que los capítulos anteriores han suministrado y con los elementos que añade el estudio de la lengua ewe [...], cuyo vocalismo parece denunciar reliquias de un antiguo lenguaje místico y secreto." Marius Schneider: El origen, S. 308.

31. Bernhard Bleibinger: Marius Schneider und der Simbolismo, S. 210-211 und 217.

32. ,[...] el zodíaco normal ocupa la zona intermedia entre los animales y el zodíaco por quintas (solar), el cual forma el círculo exterior de los tres zodíacos." Marius Schneider: El origen, S. 213.

33. Marius Schneider: El origen, S. 320-321.

34. Man denke insbesondere an den ersten Teil, in der über Quintschichtung eruierte Tonalitätskreise auch geographisch und entwicklungsgeschichtlich zugeordnet werden. Marius Schneider: Geschichte der Mehrstimmigkeit, Teil 1, Die Naturvölker, Berlin 1934.

35. Hier nicht im Sinne eines negativ konnotierten Vorurteils, sondern eines bereits zuvor bestehenden Urteils. 
Insgesamt bleibt die oft sehr spezifische Bedeutungsgebung von Phänomenen durch Schneider zu berücksichtigen. Entgegen der allgemeinen Definition erachtete er Urweltbilder nicht nur als Schauplatz von Mythen, sondern, aufgrund von darin enthaltenen geographischen Merkmalen, als Ideallandschaften und in der Folge als reale Landschaften.

„Die häufige Übereinstimmung gewisser Namen von Flüssen und Gebirgen in Regionen, die geographisch weit voneinander entfernt liegen, führt zur Annahme, dass sich die Hüter der megalithischen Philosophie bei der Benennung der Berge und Flüsse jeder Region, in der sie sich niederließen, an diese Ideallandschaft hielten.“36

Schneiders Grundidee könnte folgendermaßen umschrieben werden: Brächte man alle Urweltbilder in Deckung, so müsste das Endprodukt jene Landschaft sein, in der alle uns bekannten Mythen, Symbole und Korrespondenzsysteme ihren Anfang nahmen.

Entsprechende Geländevergleiche und Abgleichungen mit Ergebnissen aus der Ethnologie und Frühgeschichte ebenso wie selbsterstellte musikalische Migrationsskizzen ${ }^{37}$ führten Schneider zum Schluss, dass die Kultur des Urweltbildes in der Zeit des sogenannten „Megalithwesens“ in Zentral- und Westeuropa angesiedelt gewesen sein muss, dass sie Träger einer religiösen Bewegung war, die entlang der Küstengebiete ihr Weltbild und ihre Symbole verbreitete, dass sie nach Osten abwanderte und wieder zurückkehrte. Ähnlich argumentierte schon Heine Geldern. ${ }^{38}$ Mit der Idee eines westlichen Einflusses in Asien war Schneider kein Vorreiter. Vielmehr folgte er damals verbreiteten Auffassungen, betrachtet man folgenden Textausschnitt aus Steinmanns Das kultische Schiff in Indonesien.

„Die Vogelgestalt der Schiffe auf den Bronzetrommeln, die auch auf den Dajakmalereien beim Nashornvogelschiff deutlich sichtbar ist, finden wir, wenn auch stilisiert, andeutungsweise am Steven des einen Schiffes auf den Südsumatra-Stickereien zurück. Diese Übereinstimmungen bestätigen wiederum die engen Beziehungen der spätbronzezeitlichen Kultur Hinterindiens, für die Heine Geldern die Bezeichnung Dongso'n-Kultur geprägt hat, zu Indonesien und speziell zur Kunst von Südsumatra. Der Stil, der dieser Dongso'n-Kultur eigen ist, weist nach Heine Geldern eine Anzahl westlicher Elemente auf und wurzelt letzten Endes in der Bronze- und frühen Hallstattzeit Europas. Jansen [...] hat speziell auf die Beziehungen Südostasiens zur Hallstattkultur hingewiesen. In diesem Zusammenhang muss auf die auffallende Ähnlichkeit der Schiffsdarstellungen einiger sumatranischer Stickereien mit denjenigen der sog. Drachenschiffe auf Rasiermessern der späten, europäischen Bronzezeit gewiesen werden. [...] Neben der besprochenen Einwirkung der spätbronzezeitlichen Dongso'n-Kultur, die letzten Endes zum Teil auf Elemente westlicher Herkunft zurückgehen dürfte, hat Heine Geldern auch kurz auf das Vorhandensein frühchinesischer Einflüsse auf die Kunst der Dajak hingewiesen. ${ }^{\text {‘39 }}$

36. „La muy frecuente identidad de ciertos nombres de ríos y montañas en las regiones más distanciadas geográficamente induce a creer que los portadores de la filosofía megalítica solían designar los montes y ríos de cada región donde se establecían a este paisaje ideal." Marius Schneider: El origen, S. 315.

37. Marius Schneider: El origen, figura 89.

38. Hierzu: Bernhard Bleibinger: Marius Schneider und der Simbolismo, S. 246-254; vgl. Robert Heine Geldern: Die Megalithen Südostasiens und ihre Bedeutung für die Klärung der Megalithenfrage in Europa und Polynesien, in: Anthropos, 13, (1928), S. 314-315; vgl: Marius Schneider, El origen, S. 389.

39. Alfred Steinmann: Das Kultschiff in Indonesien, in: Jpek, 13. und 14. Band, (1939-1940), S. 180-181; vgl. Marius Schneider: El origen, S. 389 und 426 Anm. 42; vgl. B.A.G. Vrooklage: Das Schiff in den Megalithkulturen, in: Anthropos, 31, (1936), S. 737 und 755. . 
Den direkten Einfluss der Frühgeschichtsforschung auf Schneider, insbesondere der sogenannten Megalithforschung in Asien, verdeutlicht folgende Passage aus El origen, in der explizit auf Heine-Geldern und Speiser Bezug genommen wird.

„Nach R. Heine Geldern und F. Speiser sind die charakteristischsten Kulturelemente der Megalithkultur die zyklopischen Kontruktionen, Gedenksteine, Steine als Sitz der Seelen, kultische Steinkreise, Pfahlbauten, die Kopfjagd, Opfer von Ochsen, Ornamente in Form von Augen, Totenschiffe, die Treppen der Vorfahren, Trommeln zur Signalübermittlung, der Opferpfahl und Labyrinthe. All diese Elemente sind auch konstruktive und fundamentale Elemente unseres Korrespondenzsystems." 40

Ansätze und Ergebnisse aus der kulturhistorischen Ethnologie und der Frühgeschichte, etwa genannte Migrationstheorien, sowie Schneiders musikethnologischer Kenntnisstand bilden Grundlagen der Beweisführung in El origen. ${ }^{41}$ So betrachtet könnte sein Unterfangen als gewagter Versuch einer Interpretation von damals als gültig erachteten Paradigmen, von noch sehr begrenzten Datensammlungen und von sogenannten „supervivencias“ (dt.: „Überlebsel“, engl.: „survivals“, „symbolisms“) $)^{42}$ verstanden werden.

Aufgrund des gegebenen Rahmens können hier nur wenige Teilaspekte von Schneiders Weltbild exemplarisch wiedergegeben werden. Vorweg sei darauf hingewiesen, dass Schneider in seinem „paisaje místico“ (,mystische Landschaft“) oder „paisaje megalítico“ („megalithische Landschaft") - neben den oben erwähnten Kulturelementen und Korrespondenzmöglichkeiten Elemente verschiedenster Mythologien vereinigte. Diese stimmen zwar in vielen strukturellen Merkmalen überein, durch die sukzessive Ergänzung durch Schneider entstand jedoch etwas Neues, nämlich ein komplettiertes Gebilde, das dem Ursprung am nächsten stehen soll. Das „paisaje“ beschreibt nicht eine einzelne mythische Erzählung, sondern die Stellung des Einzelnen im kosmischen Wirken. Man könnte hier auch von einer hypothetischen alten Weltsicht sprechen, nach der sich das Individuum in einer Landschaft befindet, die es im Laufe seines Lebens und aufgrund seiner mystischen Beziehung zur göttlichen Schöpfung in Art eines Kreislaufes und in mehreren Stationen zu durchwandern hat. Es handelt sich also um ein Grundmodell des Mythischen, ein durch Addition und anschließende Filtration von elementaren Bestandteilen und Strukturen geschaffenes kompatibles Urweltbild im Sinne einer Ur-Weltsicht.

Der Leser sollte sich bei den folgenden Erläuterungen stets eine dem Weltbild inhärente analoge Denkweise - wie sie nach Schneider dem Menschen zu eigen gewesen sein soll und wie sie auch in Korrespondenztabellen noch zu Tage tritt - vor Augen halten. Begriffe wie Mars, Jupiter etc.

40. „Según R. Heine-Geldern y F. Speiser, los elementos culturales sobresalientes de la cultura megalítica son las construcciones ciclópeas, las piedras conmemorativas, las piedras como residencia de las almas, los círculos cultuales de piedras, los palafitos, la cacería de cabezas, los sacrificios de bueyes, los ornamentos en forma de ojos, los barcos funerarios, las escalas de los antepasados, los tambores para transmitir señales, la estaca de sacrificio y los laberintos. Todos estos elementos también son elementos constructivos y fundamentales de nuestro sistema de correspondencias." Marius Schneider: El origen, S. 381.

41. Bernhard Bleibinger: Marius Schneider und der Simbolismo, S. 148-170 und 241-254.

42. Dergleichen Begriffe finden sich u.a. in Fritz Graebnes Methode der Ethnologie (1911) und Edward B. Tylors Primitive Culture (1871), um nur zwei bekannte Beispiele zu nennen. Schneiders El origen handelt von „supervivencias“ in der spanischen Folklore. Siehe hierzu auch: Bernhard Bleibinger: Marius Schneider und der Simbolismo, S. 130-132. 
werden als mythologische Erscheinungen nicht nur mit Planeten, sondern auch mit den vier Elementen, mythischen Personen, Landschaftsbestandteilen, Handlungen und Konstellationen sowie mit Zahlensymbolen, Tönen und den entsprechenden Zonen in Verbindung gebracht. ${ }^{43}$ Mars erscheint beispielsweise als „montaña de Marte“ (Marsgebirge), und seine zwei durch eine Schlucht getrennten Gipfel (die wiederum Gegensätze wie Sonne und Mond oder Feuer und Wasser etc. ausdrücken sollen) werden mit Hörnern - und damit mit Mondphasen - in Beziehung gesetzt. Seine Gesamtgestalt erinnert an die Form der Sanduhrtrommel und diese wiederum symbolisiert die Inversion und in der Folge das Opfer. Sowohl die beiden Gipfel des Marsgebirges als auch die Sanduhrtrommel, stehen für das Tierkreiszeichen Zwilling, d.h. für jenen mystischen Ort, an dem sich die Transformation der menschlichen Seele bis hin zur Geburt vollzieht. Der Turm - um ein weiteres Beispiel zu nennen - wird mit den Toten in Verbindung gebracht, da sie sich auf ihm präsentieren und quasi ihren Leib den Vögeln anbieten. Der Steinerne Turm, die Baumkrone, die Leichenverbrennung und Beisetzung unter einem Steinhaufen stehen gleichermaßen für die irdische Imitation des Aufstieges der Seele zum Steingebirge. ${ }^{44}$

Schneiders Ur-Weltbild besteht aus zwei grundlegenden Zonen, dem Himmel (fa-do-sol = F-CG) und der Erde (re-la-mi-si = D-A-E-H), die durch das astrologische Zeichen des Zwilling vereint werden. Jenseits des Marsgebirges erhebt sich der Jupiterberg, dessen Silhouette einem abgeschnittenem Dreieck gleicht und damit dem Symbol für das Element Luft entspricht. Der Schlucht des Marsgebirges entspringen vier Flüsse: der Fluss der Kindheit (zum Ton D/re hin), der Fluss der Frau (zum Ton A/la), der Fluss des Mannes (zum Ton E/mi) und der Fluss des Todes (zum Ton H/si). Auf der linken Seite berührt das Gebirge das Meer der Flammen und auf der rechten Seite läuft es in einer Ebene aus. Im oberen Teil (fa-do-sol = F-C-G) gleicht es einem schwarz-weißen Wolkengebirge, im Gebirge selbst befinden sich zahlreiche Höhlen, in denen der Schmied Vulkan Donner und Blitze schmiedet. Im rechten Teil des Gebirges beginnt der Mensch - nach Schneider seinen Weg und schreitet über die Ebene D-A (llanura re-la) zum Fluss der Frau A (rio la). In dieser Zone ist die Brautzeit und physische Reife angesiedelt. Die Heirat bzw. Ehe folgt in der Zone des Tones E (mi). Nachdem - wie Schneider schreibt - der desillusionierte und traurige Mensch mit dem Berg der Schuld, Venus (monte de venus), konfrontiert wurde, obliegt ihm die Entscheidung über seinen weiteren Weg. Er kann die sumpfige Region (pantanos) mit den Jägern (cazadores) bis zum Fluss des Todes (si-fa $=\mathrm{H}-\mathrm{F}$ ) durchqueren oder der Gebirgskette der Pflicht, des Schmerzes und des Opfers den Vorzug geben. Über die Gebirgskette könnte er u.a. zu einer Reihe von Seen (lagos) im Zentrum des Weltbildes gelangen, die mit der Idee der Geburt und der mystischen Hochzeit in Verbindung gebracht werden können. In dem vom Fluss mi durschnittenen Tal leben Ackerbauern (labradores) und darüber die Eremiten (eremitas) sowie die Hirten (pastores) mit ihrem Vieh, ihren Ochsen und Kühen (bueyes und vacas, auf der Achse do-mi = C-E in der Höhe des Tones si = H). In der Zone si und links des Flusses mi befindet sich der Asket in Einsamkeit (Zuordnungen: Glückseligkeit $=\mathrm{si} / \mathrm{H}=$ Ton des mystischen Menschen und der heiligen Zahl 8). Von dort tritt der

43. Die astrologischen Tonzuordnungen bespricht Marius Schneider in El origen u.a. auf S. 206-222.

44. Marius Schneider: El origen, S. 382-383; Bernhard Bleibinger: Marius Schneider und der Simbolismo, S. 234. 


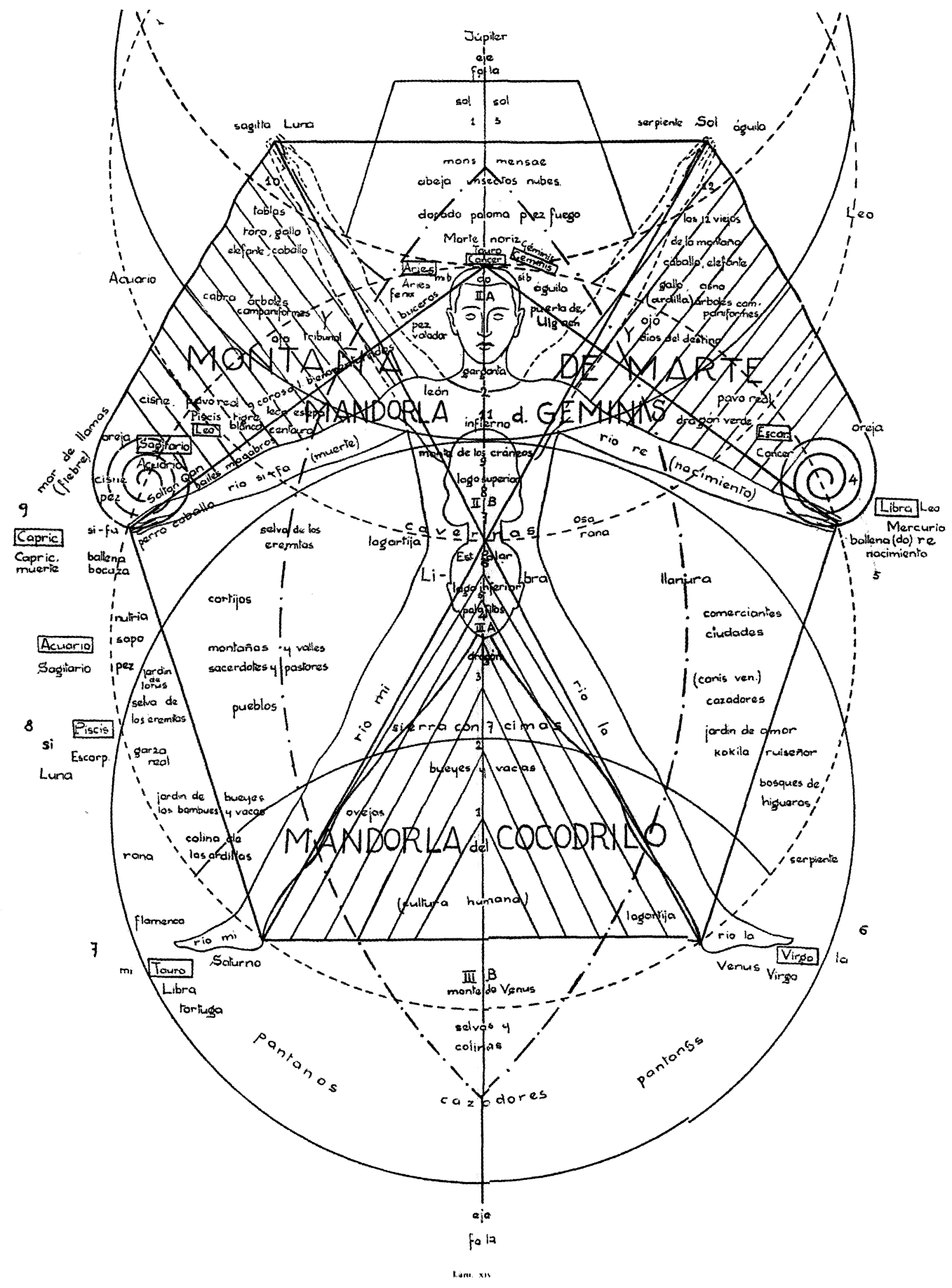

Schneiders „paisaje“

Marius Schneider: El origen, Lámina XIV 
Schamane seinen Weg in die Wüste an, die sich von den Höhlen des Gebirges zum Meer der Flammen (mar de llamas) und der schwarzen Burg erstreckt. In der Zone si-fa (Tritonus H-F) landet das Totenschiff an. Dort erwartet ein Hund die Seelen, um sie durch die Unterwelt der Mars-Burg zu geleiten. Die Anlegestelle korrespondiert mit der mystischen Zahl 9, der Zahl der Totentänze und der neun Geister des Schamanen. Die Seelen der Toten stehen nun am Scheideweg. Während sich die neun Chöre der Glückseligen zum Paradies aufschwingen, steigen die Verdammten den Weg der neun Strafen in die Hölle hinab (ausgedrückt durch das Symbol Y). Hier schließt sich der Kreis. ${ }^{45}$

Wie erwähnt, spiegelte sich nach Schneider darin eine Ur-Weltsicht einerseits und andererseits der lokale Ursprung derselben wider. Sein Erklärungsmodell des Symbolischen war aus seiner Sicht mit realen Gegebenheiten und Phänomenen verbunden.

\section{Schneider im Schaffen Cirlots}

Wie oben erwähnt, läßt sich Schneider 1949 erstmals im Schaffen Juan-Eduardo Cirlots feststellen, nämlich im Beitrag Musicalismo mágico. ${ }^{46}$ Wie Cirlot später berichtete, hatte er damals von einem seltsamen Buch gehört, dessen Autor ein in Barcelona lebender Deutscher war, den er schließlich persönlich kennenlernte. ${ }^{47}$ Bei besagtem Buch handelte es sich um El origen. In Musicalismo mágico werden auf knapp einer Seite die wichtigsten Ideen daraus zusammengefasst, etwa über Gesänge als magische Handlungen, über die Entstehung und das Wirken von Korrespondenzsystemen oder über die klingende Konzeption des Universums.

Das erstmals 1958 und bis heute in mehr als elf Neuauflagen in spanischer und englischer Sprache erschienene und Schneider mit den Worten „Al doctor Marius Schneider, en testimonio de amistad y admiración" gewidmete Diccionario de Símbolos bildet den Höhepunkt in Cirlots lexikalischem Schaffen. ${ }^{48}$ Nach den Worten Cirlots basiert sein Symbollexikon auf den symbologischen Konzepten seines Lehrers, nämlich auf denen des „ritmo común“, der Korrespondenzen und der Landschaft. Die im Vorwort erwähnte „,vergleichende Methode“ bedeutet in diesem Fall die Miteinbeziehung von Ideen von Symbolforschern verschiedenster Gebiete, etwa Guénon, Eliade und Jung. Schneiders Einfluss spiegelt sich insbesondere in der Einleitung, die ein eigenes Kapitel mit dem Titel „El <ritmo común> de Schneider“ enthält, sowie Beiträgen wider, die einen unmittelbaren Bezug zu El origen und La danza aufweisen; wie z.B. Géminis, Inversión, Paisaje, Música und Profesiones.

Noch vor Veröffentlichung seines Diccionario hatte Cirlot einen seiner Rolle als Literat entsprechenden konsequenten Schritt vollzogen, als er in La Dama De Vallcarca Schneiders

45. Marius Schneider: El origen, S. 304-320 und lámina XIV; Bernhard Bleibinger: Marius Schneider und der Simbolismo,

S. 232-239. Einige Elemente in Schneiders Beschreibung in El origen, S. 304-320, sind in lámina XIV nicht vermerkt.

46. Juan-Eduardo Cirlot: Musicalismo mágico, in: ders.: Diccionario de los Ismos, Barcelona 1949, S. 238.

47. Juan-Eduardo Cirlot: Homenaje a un gran Maestro: La simbología de Marius Schneider, in: La Vanguardia, 14. März 1969, S. 11.

48. Juan-Eduardo Cirlot: Diccionario de símbolos tradicionales, Barcelona 1958. Die folgenden Auflagen tragen nur noch den Titel Diccionario de símbolos. 
„paisaje“, d.h. einen Bestandteil von dessen Simbología in einen poetischen Simbolismo umfunktionierte. ${ }^{49}$ Cirlot beschreibt darin eine imaginäre Wanderung durch Vallcarca, einen Stadtteil Barcelonas, der für ihn von biografischer Bedeutung war. Dort lebten zeitweise einer seiner meist verehrten Komponisten, Arnold Schönberg, den er auch den „Priester der zwölf Töne“ nannte (in der „Calle Britz“) ${ }^{50}$, sein Lehrer Marius Schneider (in der Carrer Alcoi) und er selbst (in der Carrer Hercegovina). Die Verbindung zu Schönbergs Wohnung bildete eine Brücke, nämlich die Brücke von Vallcarca, und genau an dieser Stelle gabeln sich drei Straßen in Form eines Ypsilons auf, jenem Symbol, das in Schneiders Landschaft den Zwilling und dessen Arme, die Flüsse der Jugenzeit (Río de la juventud $=$ Fluss der Geburt/nacimiento, D) und des Vergessens (Río del olvido $=$ Fluss des Todes/muerte, H-F), verkörpert. La Dama De Vallcarca ist durchzogen von Aspekten aus Schneiders Landschaft, mit Geländemerkmalen wie „la montaña de Marte“, Tierdarstellungen, Farbsymbolismen und Rhythmen. Doch Cirlot übernimmt nicht nur einzelne Symbole, er verwandelt Vallcarca in Schneiders „paisaje megalítico“, in die megalithische Landschaft, und lässt den Leser den Weg des Schamanen beschreiten. In diesem Moment wird die Simbología seines Maestros zum Simbolismo. Allerdings bewahrheitet sich hier Pere Gimferrers Äußerung, dass man Cirlot schwer verstünde, wenn man El origen und La danza nicht kenne. Jedes Symbol eröffnet einen Kosmos vernetzter Symbolismen und führt in Schneiders Welt der Analogien, in der beispielsweise das Kreuz auf das Zentrum, den Baum des Lebens, das Y und damit auf eine Reihe von weiteren Deutungen verweisen kann.

Einen besonderen Fall symbologisch-symbolistischer Umdeutung bildet die Figur Bronwyn aus Franklin Schaffners Film „El Señor de la Guerra“ (engl: „The War Lord“, dt.: „Die Normannen kommen") mit Charlton Heston und Rosemary Forsyth in den Hauptrollen. Cirlot war begeisterter Kinogänger, jedoch ohne Ambitionen zu einer fortwährend ästhetischen Beurteilung. Es gab für ihn keinen schlechten Film, der nicht zumindest eine gute Minute vorzuweisen hatte, und kein cineastisches Meisterwerk, das nicht irgendwelche vergänglichen Momente in sich barg. ${ }^{51}$ Filme konnten seines Erachtens unter verschiedenen Gesichtspunkten betrachtet werden, und dazu zählte auch der des Symbols und - in Anlehnung an Eliade - der der profanisierten Mythologie. ${ }^{52}$ „El Señor de la Guerra" spielte in mythologisch aufgeladenem keltischen Ambiente und erinnerte ihn durch Motive wie Türme, Sümpfe und das Meer an die megalithische Landschaft aus El origen. In besonderem Maße konzentrierten sich seine Gedanken auf eine Szene, in der Bronwyn, die künftige Geliebte eines normannischen Ritters, nackt den Sümpfen entsteigt, d.h. auf ein Bild, das in

49. Juan-Eduardo Cirlot: La Dama de Vallcarca, in: Correo de las Artes, No. 4, 23. April 1957.

50. Cirlot schrieb bezeichnenderweise darüber: „Los objetos de orden mágico (simbólico) tienen un gran lugar en mi vida. Tomaré un único ejemplo. Una de mis veneraciones es Arnold Schönberg. Cuando me enteré que había vivido casi un año en Barcelona, en el n ${ }^{\circ} 13$ de la calle Britz, cerca del sublime barrio Vallcarca, un gueto espiritual insuperable, me lancé inmediatamente a descubrir los lugares santificados por el sacerdote de los Doce Tonos. Busqué como un loco un vestigio de su paso por este espacio“. Zitiert nach Jaime D. Parra: Cirlot Y Schneider: La Ciencia De Los Símbolos, in: Filologia Romànica, Anuari De Filologia, Volum XXI, Anys 1998-1999, Secció G, Número 9, S. 83.

51. Victoria y Lourdes Cirlot: Juan-Eduardo Cirlot: Un Boceto biográfico, S. 64.

52. „Eliade muestra que las actuales novelas, en especial de aventuras, y el cine, contienen mucha mitología $<$ profanizada>, descendida a una tercera categoría (ya que la segunda la constituyen las leyendas y los cuentos folklóricos, cual los compilados por los Grimm, Andersen y Perrault)." Juan-Eduardo Cirlot: ¿Qué es la Simbología?, in: La Vanguardia, 23.11.1968, S. 15. 
Schneiders „paisaje“ auf die Reifezeit des Menschen und nach Cirlot auf die Wiedergeburt verweist.

In der hier nur kurz zusammengefassten Handlung von Franklin Schaffners Film, tritt ein normannischer Herr namens Chrysagon sein Lehen in einem von Sümpfen umgebenen Dorf am Meer an. Die anfängliche Euphorie für Chrysagon schwindet jedoch schnell, als dieser, in einem Moment liebesbedingter Tollheit, auf der Hochzeit Bronwyns das Recht der ersten Nacht einfordert und tags darauf, entgegen der Abmachung, die Braut nicht mehr freigeben will. Nun geht der gekränkte Ehemann mit dem Häuptling der Friesen, dessen Sohn im Wehrturm Chrysagons als Geisel gehalten wird, ein Bündnis ein. Im Mittelpunkt des folgenden Geschehens steht die Belagerung und Schlacht um den Turm, in der sich Chrysagon und Bronwyn befinden. Gegen Ende des Films tötet Chrysagon in einer persönlichen Auseinandersetzung seinen Bruder, und Bronwyn entschwindet mit den Friesen übers Meer in ein ungewisses Schicksal. Die daraus entstandenen und zwischen 1967 und 1972 unter dem Titel Bronwyn ${ }^{53}$ erschienenen Gedichte enthalten denn auch die bezeichnende Widmung „A la que renace de las aguas“: „Für die, die aus den Wassern wiedergeboren wird“. Ähnliche Verweise finden sich in den Gedichten selbst.

„Renace, Bronwyn, para no para no destruir la piedra eterna; el centro, que en los centros de mi yo, te eternamente mira."
„Werde wieder geboren, Bronwyn, auf dass auf dass der ewige Stein nicht zerstört werde; das Zentrum, das in den Zentren meines Ichs dich ewiglich schaut. “54

Cirlots Motive des Zyklus und der Wiedergeburt, Bronwyn und Wasser, erscheinen hier in Zusammenhang mit dem Symbol des Steins, das wiederum auf Schneider verweist, nämlich auf dessen Idee des versteinerten schöpferischen Urklangs, der Verbindung zwischen Himmel und Erde. „La piedra eterna“, das „Zentrum in den Zentren des Ichs“, führt in dessen megalithische Landschaft, in den Mittelpunkt des Weltbildes der alten Kosmologien.

„Eine einst weit verbreitete Kosmologie, die im Spätmegalithikum ihre stärkste Ausbreitung fand, hat im Laufe der Menschheitsgeschichte ein mythisches Weltbild geschaffen, das trotz seiner unzähligen kulturgeographischen Varianten eine erstaunliche Einheit der Grundzüge bewahrt hat. Das zentrale Symbol war der Stein, bezw., der steinerne Pfeiler oder der Weltenbaum als materielles Produkt eines Himmel und Erde verbindenden, schöpferischen, aber für die Menschen fast unhörbar gewordenen Rufs." ${ }^{55}$

Die Ideenverbindung zwischen Schneider und Cirlot zeigt sich noch enger, blickt man auf die Entstehungsgeschichte der Gedichte. Wie folgendem Beispiel aus den erhaltenen Skizzen Cirlots zu entnehmen ist, ging den Bronwyn-Zyklen eine detaillierte Analyse voraus, die auf Schneiders Weltbild aufbaute.

53. Juan-Eduardo Cirlot: Bronwyn, Madrid 2001.

54. Juan-Eduardo Cirlot: Bronwyn VIII (1969), aus: ders., Bronwyn, Madrid 2001, S. 251.

55. Marius Schneider: Singende Steine, München 1978, S. 65-66. 


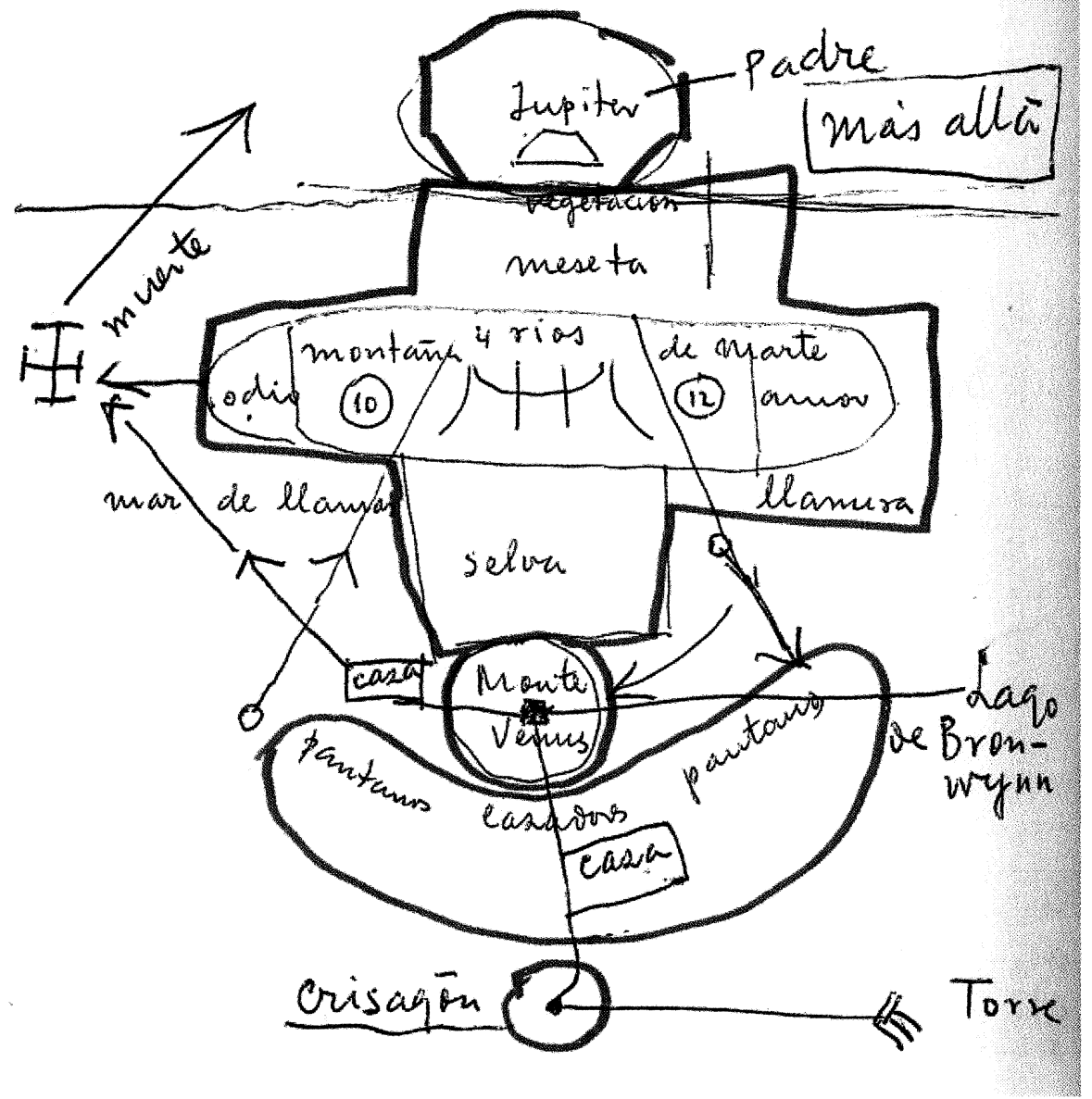

Landschaft in „El Señor de la Guerra“

Skizze aus Juan-Eduardo Cirlot: Bronwyn, hrsg. von Victoria Cirlot, Madrid: Siruela 2001, Anhang, o.S.

Am oberen Ende befinden sich der Jupiterberg und das Marsgebirge zwischen dessen beiden Gipfeln die vier Flüsse entspringen. Die Gipfel selbst stehen für Liebe (amor) und Hass (odio)

Wie im paisaje hat Bronwyn ihren Weg zu beschreiten. Sie begibt sich zum See (Lago de Bronwyn), wo sie Chrysagon trifft, dessen Turm (Torre) auf der anderen Seite der Sümpfe (pantanos) liegt. Dort entscheidet sich die weitere Geschichte. Nachdem sie ihre Liebe entdeckt haben (Monte Venus), muss sich Bronwyn durch das Meer der Flammen (mar de llamas) begeben, auf dessen anderer Seite sich der Tod (muerte; das Sterben der Männer in der Schlacht, auch der Tod von Chrysagons Bruder) ereignet. Am Ende von Bronwyns Reise steht das Entschwinden in ein ungewisses Schicksal. Cirlots skizzierter Filmverlauf schließt nicht im Fluss des Todes, sondern deutet in Richtung Jupiterberg auf ein offenes Ende. Entsprechend interpretiert Cirlot die Bedeutung 
der im Film agierenden ethnisch-symbolistisch zuordbaren Gruppen und den Aufstieg Bronwyns in einer Skizze mit dem Titel „BRONWYN = MITO COSMICO“.

Kelten $($ Celtas $)=$ Sümpfe (pantanos) - Fruchtbarkeit, Sittenverfall (fecundidad, disolución)

Normannen $($ Normandos $)=$ Turm (torre) - Schutz, Erhöhung (protección, elevación)

Friesen $($ Frisios $)=$ Meer-Schiffe (mar-naves) - Kraft, Freie (fuerza, libres)

Bronwyn, Kelten $\rightarrow$ Normannen $\rightarrow$ Friesen

Seele $($ alma $)=$ vom Himmel gefallenes Funkeln (centella caída del cielo), Dyonisos-Mythos (mito de Dionisos)

Chrysagon, Repräsentant der Transmission durch das Opfer (agente de la transmisión por el sacrificio) ${ }^{56}$

Während Kelten, Normannen und Friesen in Cirlots Darstellung mit Eigenschaften belegte Grundkonstanten und in gewissem Sinne Ebenen darstellen, die Bronwyn zu durchschreiten hat, verkörpert Bronwyn das nie Besitzbare und einen zyklischen Prozess der Erhöhung und Transformation. Kelten und Normannen versuchen Ansprüche auf sie geltend zu machen, müssen ihr jedoch Durchgang gewähren. In seiner Funktion als neuer Herr, insbesondere durch seine Bereitschaft zum Opfer in Form seiner im Kampf sterbenden Männer, läßt sich Chrysagon als Initiator dieses Durchschreitungsprozesses definieren. Die Entscheidung findet im Wehrturm statt, wo Bronwyn zur Geliebten Chrysagons wird und den Höhepunkt ihres irdischen Aufstiegs erfährt. Cirlot beschreibt den Weg Bronwyns folgendermaßen:

4. Die Entschwundene (den Friesen übergeben, mit ungewissem Schicksal)

3. Die Herrin (Gemahlin von Chrysagon)

2. Die Erschienene (im Fluss)

1. Die Unbekannte (Adoptivtochter, schlafend) ${ }^{57}$

Sowohl die erste, als auch die letzte Ebene, Anfang und Ende, dieses Prozesses umgibt die Aura des Ungewissen. Cirlot sieht darin Entsprechungen zu keltischen Feenfrauen (mujer-hada céltica). Bronwyn ist ein Analogon, und erst in der von Cirlot hergestellten Verknüpfung mit anderen Hierarchien, beispielsweise bei Jung oder in heidnischen Vorstellungen, lässt sich ihre tiefere Bedeutung wahrnehmen.

56. Juan-Eduardo Cirlot: Bronwyn, Madrid 2001, Anhang, o.S.

57. Juan-Eduardo Cirlot: Bronwyn, Madrid 2001, Anhang, o.S. Siehe folgende Seite. 

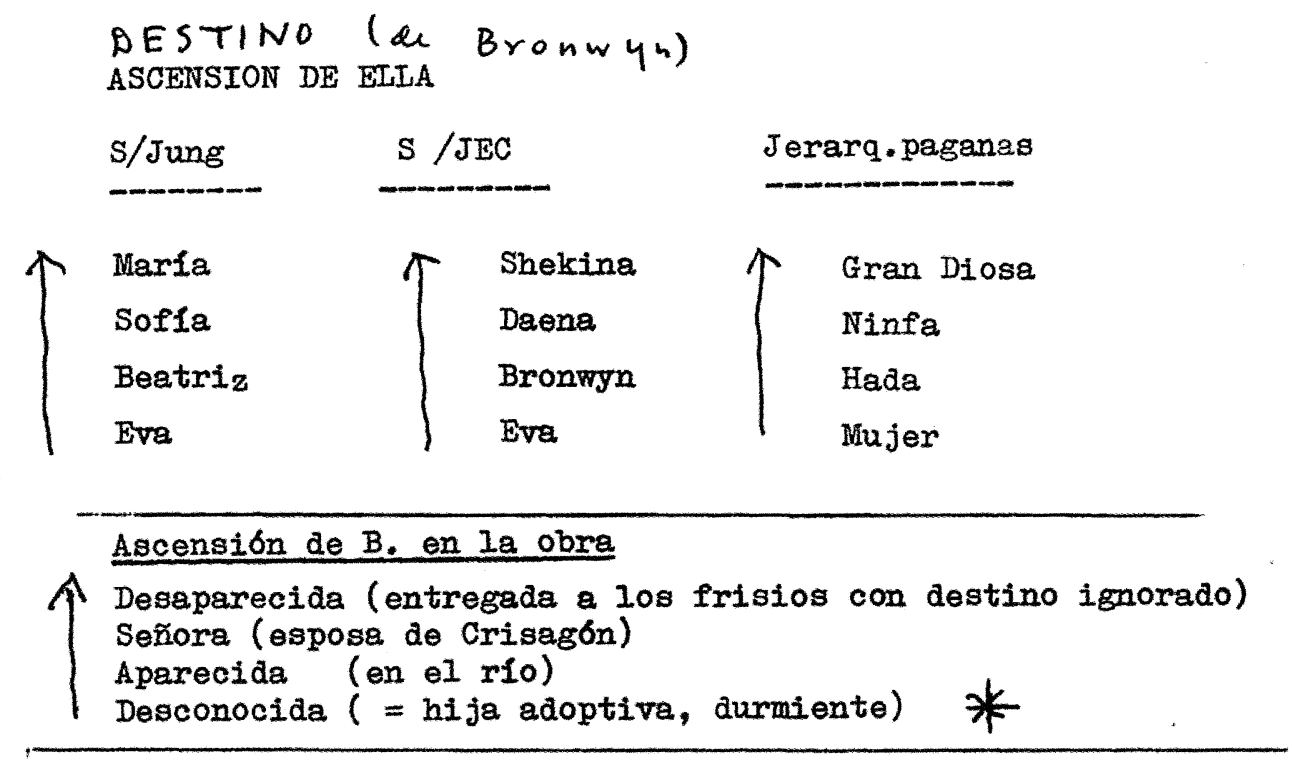

El hijo del rey, ¿signo de que años atrás pudo lo mismo suceder otra vez con una nifia?, ¿habrlan llevado a una niña a un ataque contra Brabante? ¿Browyn, princesa frisia?

* De origen y fin ignorado, signo de la mujer-hada céltica.

Aufstieg Bronwyns

Skizze aus Juan-Eduardo Cirlot: Bronwyn, , hrsg. von Victoria Cirlot, Madrid: Siruela 2001, Anhang, o.S.

Aus dieser Perspektive offenbart sich Bronwyn als Archetypus, als eine in einer mythischen Syntax Ausdruck findende Erscheinung oder, anders ausgedrückt, als Bestandteil einer modellhaften Handlung in den narrativen Mustern des Imaginären. Die Gewinnung von dergleichen Erkenntnissen allein genügte Cirlot jedoch nicht. Er brachte sie zur Anwendung, indem er nach einer analytischen Entmystifizierung den Schritt zur Remythisierung vollzog, nämlich in Form eines poetischen Simbolismo. In diesem ist Bronwyn als pars pro toto mit dem Zyklus der ewigen Wiederkehr und Schneiders welterhaltendem Opfer assoziierbar. Sie ist Abbild des Sakralen in einer vermeintlich gewesenen Alltäglichkeit (der von Charlton Heston und Rosemary Forsyth gepielten mittelalterlichen Alltäglichkeit der 1960er Jahre) reflektiert in einem modernen Mythos (Cirlots Bronwyn). Nach den erhaltenen Manuskripten bezeichnete Cirlot seinen Gedichtzyklus denn auch als „Mito Cósmico“, als kosmischen Mythos. 


\section{Schlussgedanke}

In Juan-Eduardo Cirlots Euvre sind zwei untereinander verbundene Richtungen der Symbolbehandlung auszumachen, nämlich der Simbolismo, als poetische Umsetzung, und die Simbología, als wissenschaftliche Annäherung. Beide basieren - wie gezeigt wurde - zu einem gewissen Grad auf der Daten- und Erkenntnislage der Frühgeschichte und kulturhistorischen Ethnologie der 1920er und 1930er Jahre, die er über die vergleichende Musikwissenschaft, der Disziplin seines Maestros, rezipiert und in sein Ideengebäude integriert hatte.

Während der Vorarbeit zu Bronwyn filtrierte Cirlot - im Sinne der Simbología als Wissenschaft der Symbole - Grundmuster und -motive einer erzählenden Denkenweise heraus. Der Weg dorthin führte über eine Art filmisch-mythologische Strukturanalyse, die Grundlage dazu bildeten Schneiders Korrespondenzen und megalithische Landschaft sowie dessen Idee des „ritmo común“, d.h. dessen Konzept zum assoziativen und analogen Denken. Cirlots Fazit kann folgendermaßen zusammengefasst werden: Namen ändern sich je nach Erzählung, sie sind aber nur bedingt signifikant. Wichtiger sind die hinter Personen, Parteien und Landschaftserscheinungen stehenden Wertungen und Bezugsmöglichkeiten.

$\mathrm{Zu}$ jenen Wertungen und Bezugsmöglichkeiten gelangte er über Schneiders symbologisches Modell einer alten Weltsicht; sehr deutlich zeigt sich dies an Cirlots Geländeskizzen zu „El Señor de la Guerra“/,The War Lord“, die im Grundzug Schneiders „paisaje“ wiedergeben. Dieses lieferte ihm sein auf mythischen Strukturen beruhendes Symbolbezugssystem.

Über seine Wirkung als Cirlots Lehrer in der Wissenschaft der Symbole stand Schneider zweifelsohne in Kenntnis, zumal er 1958 ein Exemplar des ihm gewidmeten Diccionario de símbolos tradicionales erhielt. $\mathrm{Ob}$ er das weitere von ihm geschaffene Bild erahnte, darüber mag indessen spekuliert werden. Fest steht, dass durch die symbolistische Umdeutung im Werk Cirlots, die auf Quintenzirkel beruhende megalithische Landschaft Schneiders remythisiert wurde, und auch Schneider Bedeutungsverschiebungen erfuhr, nämlich in persönlichen Porträts des Poeten, in denen der Lehrer, Symbolwissenschaftler und Musikethnologe zum nicht fassbaren „sabio“, „artesano“ und „guerrero“, d.h. zu einem polysignifikanten Symbol avancierte. Cirlots Rolle, betrachtete man sie aus seiner symbolistischen Perspektive, könnte als die eines Schneider zunächst unbekannten Essayisten beschrieben werden, der vom wissbegierigen Schüler zum Wortweltenschöpfer aufstieg. Im Gegensatz zu Bronwyn ist sein Schicksal jedoch nicht ungewiss.

Darüber und über unsere eigene Rolle werden wir uns nach der Veranstaltung jenes eingangs beschriebenen 4. Mai bewusst, bei der gemeinschafts- und traditionskonstituierenden Handreichungszeremonie von Kunstschaffern und Kunstreflektierern in einer zeitlos symbiotischen Szenekultur. Symbolische Systeme werden eben, wie schon Clifford Geertz im Todesjahr Cirlots schrieb, historisch konstruiert, sozial aufrecht erhalten und individuell angewendet. ${ }^{58}$

58. Clifford Geertz: The Interpretation of Cultures, New York 1973, S. 363 und 364. 